\title{
HART, BULYGIN Y RUIZ MANERO: TRES ENFOQUES PARA UN MODELO
}

\section{Regla de reconocimiento o reconocimiento de la regla}

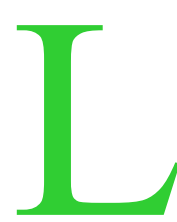

a regla de reconocimiento, versión soft de la norma fundamental ${ }^{1}$, fue enunciada por Hart como base del sistema jurídico en «El concepto de derecho», publicado originalmente en $1961^{2}$. En 1976 apareció un artículo³ en el que Eugenio Bulygin, desde una óptica dotada de mayor precisión, atribuía a Hart cierta «confusión conceptual». Juan Ruiz Manero, en $1990^{4}$, salió al cruce de la opinión de Bulygin. Así se encendió una polémica que hizo deliberada eclosión en el número 9 de Doxa $^{5}$ : Bulygin respondió a Ruiz Manero en «Algunas consideraciones sobre los sistemas jurídicos», el segundo contraatacó en «Normas independientes, criterios conceptuales y trucos verbales-Respuesta a Eugenio Bulygin» y el maestro de Buenos Aires se quedó, al menos por el momento, con la última palabra en «Regla de reconocimiento: ¿norma de obligación o criterio conceptual? Réplica a Juan Ruiz Manero».

Toda polémica tiende, por su propia dinámica, a deslizarse hacia lo histórico: expresiones del tipo «yo no dije esto sino lo otro», «jamás he sostenido semejante barbaridad», «Fulano está de acuerdo

${ }^{1}$ Acerca de la comparación entre norma fundamental y regla de reconocimiento, cfr. Guibourg, Ricardo A., Derecho, sistema y realidad, Buenos Aires, Astrea, 1986.

2 Traducción castellana de Genaro R. Carrió, Buenos Aires, Abeledo-Perrot, 1963.

3 Bulygin, Eugenio, «Sobre la regla de reconocimiento», en Derecho, filosofía y lenguaje-homenaje a Ambrosio L. Gioja, Buenos Aires, Astrea, 1976, pág. 31.

${ }^{4}$ Ruiz Manero, Juan, Jurisdicción y normas, Madrid, Centro de Estudios Constitucionales, 1990.

${ }^{5}$ Doxa, cuadernos de filosofía del derecho, Alicante, Centro de Estudios Constitucionales y seminario de filosofía del derecho de la Universidad de Alicante, 1991. 
con Mengano y no con Zutano», van adquiriendo, al ritmo de réplicas y dúplicas, creciente espacio frente a lo conceptual. En este caso, sin embargo, la claridad con que ambos polemistas sustentan sus opiniones es en todo momento apropiada para suscitar en el lector reflexiones adicionales. Estas reflexiones son las que me propongo exponer aquí.

Tanto Bulygin como Ruiz Manero critican a Hart por la circularidad con que éste define la regla de reconocimiento, pero cada uno sugiere un camino algo diferente para escapar de ese círculo.

Ruiz Manero propone definir extrasistemáticamente el concepto de juez, mediante «reglas sociales que imponen deberes y otorgan poderes». Explica que es necesario recurrir a reglas ajenas al derecho mismo para escapar de una circularidad que juzga intolerable, pero no se explaya acerca de la naturaleza de aquellas reglas. Sin embargo, justifica la aceptación de la regla de reconocimiento por referencia a reglas morales. Acaso pueda, pues, conjeturarse que aquellas reglas sociales sean también morales. Si así fuera, tanto por la referencia a la definición de los órganos primarios como por los fundamentos de la aceptación de la regla máxima, el círculo de Hart tendría una vía de escape ética.

Bulygin, en cambio, plantea la regla de reconocimiento como una regla conceptual, que hace las veces de axioma en el orden jurídico, y señala que, para actuar según reglas, no es suficiente mencionarlas o preguntarse por ellas, sino usar alguna para actuar en su consecuencia. La última regla usada (interpreto: entre las que se hayan empleado, la más alta en la cadena justificatoria), operará por sí misma como axioma y no requerirá justificación ulterior.

Ruiz Manero y Bulygin no parecen hablar el mismo idioma argumental, simplemente porque parten de distintos centros de interés y cada uno considera insatisfactorio el objetivo del otro. Bulygin pone el acento en el concepto de sistema, dando por sentado que cada persona, grupo o comunidad tendrá sus razones para justificar un sistema $u$ otro. Ruiz Manero, en cambio, explora el modo de justificar el sistema mismo y no se satisface con aquella indeterminación: está tan preocupado por la verdad y la realidad que tiende a menospreciar los argumentos formales, que en su entender dan lugar a «sistemas imaginarios, soñados o propuestos».

\section{Círculos virtuosos}

Considero necesario, ante todo, clarificar el contexto formal del debate, que gira en torno a cómo salir del círculo en el que Hart parecería quedar encerrado. 
Dentro de un sistema deductivo (como lo son los normativos y, dentro de éstos, los jurídicos) hay demostraciones disponibles (justificaciones, en un sistema non-nativo) para todos los enunciados del mismo sistema, incluidos los axiomas. Esto hace que, visto desde adentro, cualquier sistema sea circular.

Esto es precisamente lo que advierte Hart cuando distingue, frente a la regla de reconocimiento, el punto de vista interno del externo. E incluye en el sistema jurídico dicha regla «vista desde abajo». En este sentido, afirma, la regla de reconocimiento no es válida ni inválida, porque ella misma contiene los criterios de validez. Y tampoco es verdadera ni falsa, porque, vista desde abajo (desde el punto de vista interno) es una norma (secundaria, no primaria «de obligación») que se usa y acepta (se presupone, diría Kelsen) cuando se afirma la validez de una regla. En cambio, desde el punto de vista externo (desde arriba y fuera del sistema), la RR presupone una afirmación: que esa RR es aceptada por la comunidad. En ese sentido la regla de reconocimiento «existe» (es verdadera, diría Ruiz Manero) cuando puede ser demostrada por referencia a la práctica efectiva de la comunidad. Dice Bulygin que las reglas conceptuales son como definiciones. Pero, como sabemos, hay definiciones estipulativas (que proponen, deciden o imponen un significado) y definiciones informativas (que describen la aceptación social de cierto significado, acaso estipulado en algún momento pretérito). Si aplicamos esta nomenclatura a la teoría de Hart, podríamos decir que la regla (conceptual) de reconocimiento es una definición estipulativa hacia adentro (como patrón de validez de las demás reglas que se reconocen por aplicación de ella) y una definición informativa hacia afuera (porque describe la aceptación comunitaria de aquella estipulación interna). Si esta última descripción corresponde a la realidad, la RR será verdadera (con una verdad extrasistemática, ya que desde el punto de vista interno los valores de verdad no son predicables de la RR).

Hart, después de todo, hace lo mismo que Kelsen: ambos usan la regla máxima (la que enumera la pertenencia directa de las reglas independientes, como diría Bulygin) como techo del sistema jurídico (pieza integrante del mismo sistema) y, a la vez, como gancho para colgar ese sistema de la realidad (eficacia del sistema para Kelsen, práctica efectiva de la comunidad para Hart). Tanto Kelsen como Hart, pues, hacen esfuerzos teóricos para escapar del círculo, actitud que les reporta no pocas dificultades ${ }^{6}$.

Esta aversión a la circularidad en pro de un anclaje empírico o moral parece una característica propia de la teoría jurídica. Los sistemas

${ }^{6}$ Guibourg, 1986. 
más tradicionalmente formales (lógica, geometría) tienen menos necesidad de insistir en su relación con la realidad, acaso porque la utilidad práctica de su estructura formal es más reconocida y porque su propio prestigio científico está mejor establecido. En estas condiciones, reconocen sin ambages que sus axiomas se aceptan sin demostración; no porque no tengan demostraciones a mano, sino porque la demostración de los axiomas cerraría el círculo de la deductibilidad y nada agregaría al conocimiento del ámbito intrasistemático.

Desde luego, lo que no está contenido en tales sistemas es el repertorio de las razones que nos llevan a preferir un sistema (definido y construido a partir de sus axiomas) a otro sistema (definido y construido a partir de un conjunto diferente de axiomas). En este punto es especialmente plausible la tesis de Bulygin: es preciso identificar un sistema antes de averiguar si es preferible a otro, y para identificarlo no hace falta en absoluto justificar ni demostrar sus axiomas. Tal justificación o demostración es útil, en cambio, para preferirlo.

Ahora bien, ¿por qué hemos de preferir un sistema a otro?

\section{La calesita de los modelos}

El problema de la representación (sistemática) del conocimiento de una realidad jurídica es apenas un caso particular de la relación genérica entre realidad y modelo. Ningún modelo es estrictamente «verdadero», en el sentido de que ninguno es idéntico a la realidad modelizada. Pero algunos modelos son más convenientes que otros (es decir, nos convienen más que otros), siempre por razones ajenas al modelo mismo. Un modelo podría ser consistente, deductivamente completo y hasta estéticamente hermoso, pero completamente inútil.

Desde luego, entre las razones de la preferencia figura normalmente cierta correspondencia entre la realidad y el modelo (la misma que se exige entre una proposición y un estado de cosas para llamar a aquélla verdadera). Pero tal correspondencia es siempre escasa, ya que el modelo es, en todos los casos, una representación (deliberadamente) empobrecida de la realidad. Y además -especialmente en los modelos más complejos- se halla sujeta a numerosas e intrincadas decisiones metodológicas que sirven de intermediarias implícitas entre ambos términos de la correspondencia, de modo que, cuanto más abstracto es el modelo, tanto más tenue es su «verdad» o su «falsedad».

Al lado de la correspondencia, suelen usarse otros criterios: la claridad y la sencillez de un modelo en comparación con otro (caso 
del heliocentrismo frente al geocentrismo), la certeza con que cierto modelo dé respuesta a lo que previamente hemos identificado y seleccionado como enigma interesante (caso de Ruiz Manero con los sistemas «reales»), o aun la posición de privilegio que el modelo asigne a su constructor (caso del modelo descriptivo racista, que nunca es invocado para afirmar que quien lo sostiene pertenezca a una raza «inferior»).

Pero Ruiz Manero (como Nino con sus normas morales y su definición fáctica de la función judicial, como MacCormick con sus reglas sociales, como Kelsen con su poco consistente eficacia, como Hart con su más pragmática práctica social) se empeña en buscar alguna salida verdadera para la insoportable circularidad del derecho. Cada autor intenta elegir entre varios modelos mediante un criterio único... que sólo podría hallarse fuera del modelo a escoger. En realidad, todos los criterios se hallan fuera del modelo. ¿Por qué un único criterio? Algunos modelos pueden ser más verdaderos que otros (si su correspondencia es mayor, o si los rasgos en los que esa correspondencia se verifica nos parecen más relevantes para nuestro uso). Pero ¿hay acaso una verdad en materia de modelización? Recordemos que la correspondencia -aunque importante y, en algún aspecto, necesaria- no es el único criterio útil para la construcción o elección de modelos.

\section{Conclusión}

Lo expuesto hasta ahora parece, por cierto, más compatible con la opinión de Bulygin que con la de Ruiz Manero. Creo conveniente, sin embargo, enfatizar una conclusión más genérica. La circularidad interna de los modelos es normal y no es incompatible con la existencia de criterios plurales de elección de modelos (o, naturalmente, de construcción de los modelos que luego querremos elegir). Pero el criterio que usemos para tal elección no depende tanto de la justificación individual de los axiomas o de los principales lineamientos estructurales del modelo, sino principalmente de los servicios que el modelo nos presta como un todo y, casi siempre, de la facilidad con la que consigamos hacer coincidir los elementos del modelo con los que previamente hemos identificado o aceptado como rasgos relevantes de la realidad.

En otras palabras, nuestra elección de un modelo parece depender, en parte, del modo en que el nuevo modelo coincida con otro modelo anterior, acaso más complicado o defectuoso pero normalmente aceptado: a esto llamamos correspondencia, ya que el conocimiento previo que tenemos de la realidad no es sino otro modelo. Y 
la opción que adoptemos depende también de otras condiciones pragmáticas de la relación entre tales modelos, siempre juzgadas desde nuestros propios intereses. Tales intereses no han de entenderse necesariamente como individuales, sino como preferencias compartidas por el grupo describiente. Este grupo, tanto más eficazmente cuanto mayores sean su amplitud y su perdurabilidad, tiende a consolidar aquellas preferencias con el nombre de valores y a consagrar como verdades los modelos descriptivos elegidos en función de aquéllas. El proceso social que conduce a tal resultado no es otro que la mutua reiterada confirmación de intereses y modelos en la opinión de las personas, fenómeno que la conciencia popular denomina a veces darse manija.

Como integrantes de la sociedad, no somos ajenos a valores y verdades que provienen del «darse manija» en el que estamos insertos, pero esta inevitable (e indispensable) circunstancia no debería privarnos de examinar en cada momento modelos alternativos. Y requerir que tales modelos se ajusten precisamente a las «verdades» dependientes de otros modelos no contribuye precisamente a esa apertura. En cierta época la teoría de Kelsen era anatematizada con una pregunta: «¿Dónde está Dios en la teoría pura?» La pregunta retórica implicaba priorizar el origen divino del derecho como característica relevante de cualquier teoría jurídica y rechazar toda reflexión que fuese contraria o aun indiferente a aquella tesis. Algo semejante hacemos hoy cuando escrutamos los sistemas normativos alzando en nuestras manos el báculo inapelable de la verdad. 